\title{
A New Comprehensive Educational Group Program for Older Adults with Cognitive Complaints: Background, Content, and Process Evaluation
}

Citation for published version (APA):

Hoogenhout, E., De Groot, R., \& Jolles, J. (2010). A New Comprehensive Educational Group Program for Older Adults with Cognitive Complaints: Background, Content, and Process Evaluation. Educational Gerontology, 37(1), 51-73. https://doi.org/10.1080/03601277.2010.515888

DOI:

10.1080/03601277.2010.515888

Document status and date:

Published: $14 / 12 / 2010$

Document Version:

Peer reviewed version

Document license:

CC BY-NC-ND

Please check the document version of this publication:

- A submitted manuscript is the version of the article upon submission and before peer-review. There can be important differences between the submitted version and the official published version of record. People interested in the research are advised to contact the author for the final version of the publication, or visit the DOI to the publisher's website.

- The final author version and the galley proof are versions of the publication after peer review.

- The final published version features the final layout of the paper including the volume, issue and page numbers.

Link to publication

\section{General rights}

Copyright and moral rights for the publications made accessible in the public portal are retained by the authors and/or other copyright owners and it is a condition of accessing publications that users recognise and abide by the legal requirements associated with these rights.

- Users may download and print one copy of any publication from the public portal for the purpose of private study or research.

- You may not further distribute the material or use it for any profit-making activity or commercial gain

- You may freely distribute the URL identifying the publication in the public portal.

If the publication is distributed under the terms of Article $25 \mathrm{fa}$ of the Dutch Copyright Act, indicated by the "Taverne" license above, please follow below link for the End User Agreement:

https://www.ou.nl/taverne-agreement

Take down policy

If you believe that this document breaches copyright please contact us at:

pure-support@ou.nl

providing details and we will investigate your claim.

Downloaded from https://research.ou.nl/ on date: 26 Apr. 2023 
A comprehensive educational group intervention for older adults with cognitive complaints:

background, content, and process evaluation 


\begin{abstract}
This paper presents a comprehensive intervention for older adults with cognitive complaints. It offers psycho-education about cognitive aging and contextual factors, focuses on skills and compensatory behavior, and incorporates group discussion. The intervention reduced negative emotional reactions towards cognitive functioning in healthy women aged 60 to 75 years. Its background and content are described in detail to enable application and replication. To investigate the possibility for large-scale implementation, a process evaluation was carried out. The results support participants' appreciation and point to better self-evaluations after intervention. This intervention may offer a valuable contribution to public health care for older adults.
\end{abstract}




\section{Introduction}

Complaints about cognitive functions are highly prevalent, especially in older adults. Ponds and colleagues (1997), for example, showed that the prevalence of memory complaints is 41 percent in adults aged 54 to 66 years and 52 percent in adults aged 69 tot 86 years. Although prevalence rates varied significantly depending on the study sample and the way in which cognitive complaints were measured and defined (Jonker, Geerlings, \& Schmand, 2000; Mendes et al., 2008), results of other community-based studies were in line with these findings (Blazer, Hays, Fillenbaum, \& Gold, 1997; Jonker, Launer, Hooijer, \& Lindeboom, 1996; Mendes et al., 2008; Minett, Da Silva, Ortiz, \& Bertolucci, 2008). It is thus clear that a common complaint of normally aging individuals refers to cognitive changes. The presence of such perceived cognitive losses significantly contributes to a lowered quality of life (Mol et al., 2007; Mol, van Boxtel, Willems, Verhey, \& Jolles, 2009). These cognitive problems are a source of worry and frustration for many aging individuals. Some of them are even afraid that this may be a sign of a degenerative disorder, like dementia (Commissaris et al., 1993; Commissaris, Ponds, \& Jolles, 1998; Mol, Ruiter, Verhey, Dijkstra, \& Jolles, 2008).

Approximately eleven percent of all community dwelling adults with memory complaints seems interested to participate in some sort of intervention. Education and memory training are the most preferred forms of intervention (Commissaris et al., 1998). Many individuals with perceived cognitive problems appeal on specialized healthcare services, like memory clinics (Comijs, Dik, Aartsen, Deeg, \& Jonker, 2005; Verhey et al., 2007). These facilities however offer highly specialized care (i.e., aimed at the identification and treatment of demented individuals) and are therefore costly (Verhey et al., 2007). There is thus a need for more appropriate and easily accessible interventions for relatively healthy older adults with cognitive complaints, especially in the face of our rapidly aging Western society.

In the past decades many health care practitioners and researchers have devoted themselves to the development and evaluation of cognitive interventions for older adults. There is a widespread variation in types of interventions (Floyd \& Scogin, 1997; Glisky \& Glisky, 2005; Rebok, Carlson, \& Langbaum, 2007; Verhaeghen, Marcoen, \& Goossens, 1992). Many have their roots in the informationprocessing framework of cognitive aging, which states that normal age-related 
changes in memory are linked to changes in other cognitive domains or structures (Zacks, Hasher, \& Li, 2000), like cognitive slowing (Salthouse, 1996) or problems in inhibitory functions (Craik \& Bialystok, 2006; Van Hooren, Valentijn, Bosma, Ponds, Van Boxtel et al., 2007). The 'use it or lose it' hypothesis (Salthouse, 2006), for example, is a popular model for such interventions (McDougall, 2009). These interventions assume that older adults have the cognitive plasticity to benefit from cognitive training. Their primary aim is thus to improve cognitive function per se or prevent it from relapsing (Hess, 2005; McDougall, 2009). Such interventions usually involve some form of cognitive training (e.g., one or more mnemonic techniques like the method of loci, or visual imagery) (Floyd \& Scogin, 1997; Rebok et al., 2007; Verhaeghen et al., 1992). A very extensive study to the effects of cognitive training was ACTIVE (Advanced Cognitive Training for Independent and Vital Elderly), which compared three different cognitive training interventions (i.e., memory, reasoning, and speed of processing training) to a no-contact control group (Ball et al., 2002; Jobe et al., 2001). Such cognitive interventions typically brought about taskand domain-specific effects that were maintained for a considerable period of time (Ball et al., 2002; Rebok et al., 2007; Verhaeghen et al., 1992). Older adults thus benefitted from it. Effects however hardly generalized to other cognitive domains (Rebok et al., 2007; Verhaeghen et al., 1992), and did not lead to an increase in subjective cognitive functioning, well-being (Floyd \& Scogin, 1997), or everyday functioning (Willis et al., 2006). Consequently, it has been stated that future intervention studies should find a way to increase awareness, knowledge, and subjective cognitive functioning, and decrease negative beliefs and negative memoryrelated affect (Floyd \& Scogin, 1997; Hohaus, 2007; Rebok et al., 2007; Verhaeghen et al., 1992). This requires an alternative approach.

The current paper presents a new comprehensive educational group intervention for healthy older adults with perceived cognitive problems. A randomized controlled trial has revealed that this intervention was effective in reducing negative emotional reactions towards cognitive failures in healthy women, aged 60 to 75 years, with cognitive complaints (Hoogenhout, De Groot, Van der Elst, \& Jolles, under review). A common problem in the intervention literature is that a detailed description of evaluated intervention programs lacks (Floyd \& Scogin, 1997; Jobe et al., 2001; Schreurs, Colland, Kuijer, De Ridder, \& Van Elderen, 2003; Verhaeghen et al., 1992). This may hamper the accumulation of knowledge and 
improvement of care (Schreurs et al., 2003). The current study therefore describes the intervention's background and content in detail in order to enable application and replication by other researchers or practitioners in the field of healthcare or social gerontology. Finally, for large-scale implementation it is not only important to know whether an intervention is effective, but also whether participants accept it (Grol \& Wensing, 2006; Linnan \& Steckler, 2002; Parisi, Greene, Morrow, \& Stine-Morrow, 2007; Schreurs et al., 2003). For that reason a process evaluation was carried out in which participants' appreciation of the intervention and their self-evaluations after participation were investigated. The background of this new intervention program is given in the next paragraph.

\section{Background}

It seems important to further consider the nature of cognitive complaints in healthy older adults first. Aging is often accompanied by actual changes in cognitive functions, like memory and learning (Craik \& Salthouse, 2000), speed of information processing (Salthouse, 1996), inhibitory functions and executive functions (Craik \& Bialystok, 2006; Craik \& Grady, 2002; Van Hooren, Valentijn, Bosma, Ponds, Van Boxtel et al., 2007). Subjective cognitive complaints may be indicative for actual agerelated changes in cognitive functions (Jorm, Christensen, Korten, Jacomb, \& Henderson, 2001). Furthermore, they have some predictive value for Mild Cognitive Impairment (Petersen et al., 1999; Winblad et al., 2004), or even dementia (Geerlings, Jonker, Bouter, Ader, \& Schmand, 1999; Jonker et al., 2000). Yet, many studies showed that the association between subjective and objective cognitive functioning is weak (Kliegel, Zimprich, \& Eschen, 2005; Minett et al., 2008; Mol, van Boxtel, Willems, \& Jolles, 2006). In fact, subjective cognitive complaints seem stronger related to non-cognitive factors. This has been found in studies involving, for example, metamemory (Comijs, Deeg, Dik, Twisk, \& Jonker, 2002; Mol et al., 2008; Ponds \& Jolles, 1996), depressive affect (Cargin, Collie, Masters, \& Maruff, 2008; Comijs et al., 2002; Kliegel \& Zimprich, 2005; Zimprich, Martin, \& Kliegel, 2003), personality traits (Comijs et al., 2002; Kliegel \& Zimprich, 2005; Ponds \& Jolles, 1996), and health (Comijs et al., 2002). The primary problem of the majority of older adults is thus a perceived cognitive loss that is often independent of actual cognitive changes. 
It can thus be questioned whether much is to be gained by trying to enlarge cognitive capacity alone, while non-cognitive factors are ignored (Stuss et al., 2007). Accordingly, there is growing interest in interventions that adopt a more multidimensional approach to cognitive aging (McDougall, 2009). Such interventions combine, for example, strategy training with cognitive restructuring (Lachman, Weaver, Bandura, Elliott, \& Lewkowicz, 1992), psychosocial training (Stuss et al., 2007; Winocur, Palmer et al., 2007), and education about metacognitive processes (Valentijn et al., 2005; West, Bagwell, \& Dark-Freudeman, 2008) and about other contextual factors (Hohaus, 2007; Mohs et al., 1998; Troyer, 2001; Van Hooren, Valentijn, Bosma, Ponds, van Boxtel et al., 2007). These interventions more or less fit a contextual framework of cognitive aging that was proposed by Hess (2005). He argued for the consideration of a broader constellation of factors as determinants of both intra-individual change and inter-individual variation in memory functioning, in addition to changes in the integrity and efficiency of the information-processing system. Examples of such contextual factors are: social context, health, lifestyle, negative age-stereotypes, personal goal setting, and beliefs about aging (Hess, 2005). Studies that investigated the effectiveness of such multidimensional cognitive interventions greatly differed in study design and outcome, with effects established on subjective cognitive functioning (Hohaus, 2007; Lachman et al., 1992; Mohs et al., 1998; Troyer, 2001; Valentijn et al., 2005; Van Hooren, Valentijn, Bosma, Ponds, van Boxtel et al., 2007; West et al., 2008; Winocur, Craik et al., 2007), psychological wellbeing (Winocur, Craik et al., 2007; Winocur, Palmer et al., 2007), or objective cognitive performance (Craik et al., 2007; Hohaus, 2007; Levine et al., 2007; Mohs et al., 1998; Troyer, 2001; Valentijn et al., 2005; West et al., 2008).

These findings are very promising. Unlike cognitive training interventions that fit the information-processing framework of cognitive aging, such multidimensional interventions exhibit significant effects on aspects of subjective cognitive functioning and wellbeing. Thus, multidimensional interventions with a strong educational component that take both cognitive and non-cognitive factors into account, might meet the need for more effective interventions for older adults with cognitive complaints that was expressed by other researchers (Floyd \& Scogin, 1997; McDougall, 2009; Rebok et al., 2007; Verhaeghen et al., 1992). 


\section{A new comprehensive educational group program}

In line with this growing enthusiasm for multidimensional cognitive interventions for older adults, we developed a new comprehensive educational group program that has evolved from previous successful intervention studies by our research group (Commissaris, Verhey, \& Jolles, 1996; Valentijn et al., 2005; Van Hooren, Valentijn, Bosma, Ponds, van Boxtel et al., 2007). The intervention included eight 1.5-hour sessions in four consecutive weeks and was offered in a small group format with six to nine participants per group. Its primary aim was to increase subjective cognitive functioning. In our opinion the fundamental problem of our target group was a perceived cognitive deficit that is related to, for example, negative feelings about cognitive functioning, but has limited predictive value for actual objective cognitive loss. We recently carried out a randomized controlled trial (Hoogenhout et al., under review) with an experimental and waiting list control condition. We included a carefully selected homogeneous sample of 60 healthy community dwelling older women aged 60 to 75 years with age-related perceived cognitive losses. A significant reduction in negative emotional reactions towards cognitive functioning was found in the experimental group compared to the waiting list control group one week after intervention. Theoretical perspectives and research findings provide a framework for the intervention's content.

The intervention had a strong educational focus. It offered psycho-education about normal age-related changes in memory, speed of information processing, attention capacity and executive functions (Craik \& Bialystok, 2006; Craik \& Grady, 2002; Salthouse, 1996; Van Hooren, Valentijn, Bosma, Ponds, Van Boxtel et al., 2007). Differences between normal age-related cognitive changes and cognitive decline in dementia were explained. It was emphasized that the presence of perceived cognitive problems has limited predictive value for Mild Cognitive Impairment or dementia (Winblad et al., 2004). Furthermore, the influence of several contextual factors (e.g., health, lifestyle, psychosocial functioning, beliefs, and negative aging stereotypes) on cognitive functioning was considered (Hess, 2005; Mol et al., 2008). A fundamental premise is that psycho-education enhances knowledge and increases individuals' insight into their own functioning. Knowledge is thought to enhance feelings of control (Lachman, 1991, 2000) and to modify negative beliefs (Troyer, 2001). It has a powerful compensatory and enriching effect, thus perceived cognitive losses could be overcome by the development of pragmatic knowledge (Bäckman \& 
Dixon, 1992; Baltes \& Baltes, 1990). The intervention emphasized the importance of finding a balance between gains and losses and fitted the ideas of Baltes and Baltes (1990) about successful aging through selection, optimization, and compensation. Selection refers to the process of adjusting expectations and changing personal goals to permit subjective experience of satisfaction and control. Optimization reflects the view that people engage in behaviors to enrich and augment their general reserves. Compensation results from a discrepancy between the level of performance, and situations and goal characteristics (Baltes \& Baltes, 1990). It enables individuals to adapt their behavior and implement appropriate strategies in everyday life to cope with this discrepancy (Bäckman \& Dixon, 1992; Dixon, 1995). More information was offered about skills and commonly applicable compensation strategies. Several principal mechanisms and forms of compensatory behavior were discussed (e.g., use of external aids and internal mnemonics, investing more time and effort) (Bäckman \& Dixon, 1992; Dixon, 1995; Dixon, de Frias, \& Bäckman, 2001). The importance of changing goals and expectations was emphasized (Bäckman \& Dixon, 1992), and the compensatory technique of Goal Management was introduced (Levine et al., 2000; Levine et al., 2007; Van Hooren, Valentijn, Bosma, Ponds, van Boxtel et al., 2007). Another important aspect of the intervention was group discussion (Flynn \& Storandt, 1990; Valentijn et al., 2005) about societal and personal beliefs, negative aging stereotypes (Hess, 2005; Mol et al., 2008), and pessimistic and maladaptive attributions (Commissaris et al., 1993; Commissaris et al., 1998; Lachman \& McArthur, 1986). This may contribute to better adaptation to age-related cognitive losses (Lachman, 1991).

\section{Methods}

\section{Intervention program}

The intervention program consisted of eight sessions with two sessions a week for four consecutive weeks. In line with findings from previous studies regarding optimal intervention design (Flynn \& Storandt, 1990; Verhaeghen et al., 1992), each session lasted for 1.5 hour and was offered in a small group format with six to nine participants per group. A healthcare psychologist and a research neuropsychologist facilitated all sessions. At the start of the intervention each participant received a 
workbook in which course information (i.e., session summaries, registration forms, and handouts) could be collected and notes could be taken.

The intervention was offered in a structured manner and within a standard time frame. Each session started with the evaluation and recapitulation of the content of the previous session. Homework assignments were discussed and questions were answered. In addition, themes and topics were introduced in short blocks supported by a PowerPoint slideshow with handouts. After each block, beliefs and attitudes with respect to a specific theme were shared and discussed within the group. Each session ended with a summary of the session's themes and topics, and a short preview of the homework assignments.

The intervention's content is listed in Table 1. Session 1 served as an introductory session in which aims and themes of the intervention were introduced. Education about cognitive aging (e.g., normal versus pathological and successful aging) and subjective forgetfulness was offered. Furthermore, several contextual factors (e.g., physical and mental health, environmental demands, societal norms and personal beliefs) were considered. Finally, several negative aging stereotypes were discussed. Session 2 offered education about brain development and cerebral function, and information processing. Furthermore, several cognitive functions (i.e., memory, attention, and executive functions), and age-related changes in cognitive functions (e.g., memory decline and mental slowing) were considered. Session 3 further examined the interaction between memory and other cognitive functions (e.g., attention and executive functions). Education about planning, executive function and goal management was offered, and the concept of successful aging and relevant contextual factors was further discussed. Session 4 elaborated upon the differences between pathological aging versus normal and successful aging. Information about the prevalence and incidence as well as symptoms of dementia was offered. Finally, the influence of health and lifestyle on cognitive aging was discussed, and education about optimization and enhancing general reserve was offered. 
Table 1 Summary of the intervention program

\begin{tabular}{|c|c|c|}
\hline Session & Content & Homework \\
\hline \multirow[t]{6}{*}{1} & - First acquaintance & - Reading the summary \\
\hline & - Introduction to the intervention program & - Personal goals and expectations \\
\hline & - Overview of themes & - Cognitive diary \\
\hline & - Cognitive aging and subjective forgetfulness & - Personal names for mental slips \\
\hline & - Contextual factors & \\
\hline & - Aging stereotypes & \\
\hline \multirow[t]{4}{*}{2} & - Successful aging & - Reading the summary \\
\hline & - Brain and cognition & - Cognitive diary \\
\hline & - Information processing and memory & - Speed and attention in daily life \\
\hline & - Attention and mental slowness & \\
\hline \multirow[t]{3}{*}{3} & - Planning and executive functioning & - Reading the summary \\
\hline & - Absent-minded slips & - Planning everyday tasks \\
\hline & - Successful cognitive aging and contextual factors & - Absent-minded slips \\
\hline \multirow[t]{4}{*}{4} & - Health & - Reading the summary \\
\hline & - Lifestyle & - Contextual factors in own situation \\
\hline & - Normal aging versus dementia & \\
\hline & - Optimization and enriching general reserve & \\
\hline \multirow[t]{4}{*}{5} & - Psychological factors & - Reading the summary \\
\hline & - Vicious circle of forgetting & - Getting older, what goes right? \\
\hline & - Societal and personal beliefs and expectations & - Spontaneous strategy use \\
\hline & - Adjusting expectations and personal goals & \\
\hline \multirow[t]{6}{*}{6} & - Compensation versus restoration & - Reading the summary \\
\hline & - External strategies & - Compensation in daily life \\
\hline & - Internal strategies & - Preventing absent minded slips \\
\hline & - Environmental demands & \\
\hline & - Investing more time and effort & \\
\hline & - Planning and goal management & \\
\hline \multirow[t]{3}{*}{7} & - Investing more time and effort & - Reading the summary \\
\hline & - Planning and goal management & - Goal management in daily life \\
\hline & - Preventing and handling time pressure & - Time pressure in everyday tasks \\
\hline \multirow[t]{2}{*}{8} & - Recapitulation of themes & - Reading the summary \\
\hline & - Generalization & - Generalization \\
\hline
\end{tabular}

Session 5 offered education about the influence of psychological factors and mental wellbeing (e.g., depressive affect) on cognitive aging. The vicious circle of forgetting was discussed (i.e., perception of memory decline may lead to a lack of confidence and loss of control, which in turn may lead to more perceived memory problems). Furthermore, other contextual factors like environmental demands, and societal and personal beliefs and norms were discussed. Finally, education about the 
necessity to adjust expectations and personal goals was offered. Session 6 introduced the concept of compensation and explained the difference with restoration of function. Several forms of compensatory behavior were discussed (i.e., use of external aids, internal mnemonics, anticipating on environmental demand and reliance on others, investment of more time and effort). Examples of external and internal strategies were offered. Finally, the technique of goal management was considered. Session 7 further elaborated on the importance of investing more time and effort in everyday memory demanding tasks, and offered more extensive information about goal management. Session 8 served as a summary in which all themes were recapitulated on. Furthermore, the importance of generalization to everyday life was discussed.

\section{Participants and procedure}

Participants were recruited through advertisements in local and regional weeklies and through announcements on a regional radio station. Interested individuals could contact the researchers by telephone to receive more information about the intervention program and the study. A telephonic semi-structured interview was conducted in which participants were screened for the most important inclusion criteria (i.e., being a woman, aged between 60 and 75 years, reporting age-related cognitive complaints and/or concerns about becoming demented, good comprehension of the Dutch language). Participants were excluded if they reported any previous neurological disease (e.g., stroke or dementia) or psychiatric disorder (e.g., major depressive disorder or schizophrenia). An additional exclusion criterion was a score of 24 or lower on the Mini-Mental State Examination (Folstein, Folstein, \& McHugh, 1975).

Eligible individuals were sent an information letter about the intervention program and effect evaluation. In favor of the randomized controlled effect evaluation (Hoogenhout et al., under review), people who were willing to participate were randomly assigned to either an experimental or a waiting-list control group. All participants received an individual intake interview. Afterwards a double baseline cognitive assessment was carried out with approximately one week in between. Additionally, all participants filled in several self-report questionnaires. Within one or two weeks after baseline assessment, participants in the experimental condition were offered the intervention program. Participants in the control condition were placed on a waiting list. Approximately seven weeks after the start of the study, a follow-up 
assessment was carried out in all participants. Afterwards, participants in the waiting list control condition were offered the intervention program at the end of which they filled in the questionnaires again. The medical ethics committee of the Maastricht University Medical Centre approved the study and all participants gave their informed consent. A summary of the procedure and flowchart of participants is offered in Figure 1.

In addition to age and MMSE-score (Folstein et al., 1975), several other background variables were assessed. Educational level was measured on an 8-point ordinal scale, ranging from primary education to university education (De Bie, 1987). Information about marital status was collected (married or unmarried). Two subscales of the Eysenck Personality Inventory (EPQ; Sanderman, Arrindell, Ranchor, Eysenck, \& Eysenck, 1995) were administered to measure neuroticism (e.g., being emotional unstable), and extraversion (e.g., being talkative). These subscales consisted of 22 and 19 dichotomous items (i.e., $1=$ yes, $0=$ no). Higher scores indicated more neuroticism or extraversion. The Centre of Epidemiologic Studies Depression Scale (CES-D; Bouma, Ranchor, Sanderman, \& Van Sonderen, 1995) was administered to measure depressive symptomatology. It contained 20 statements concerning depressive symptoms (e.g., feeling lonely) in the week prior to test administration. Participants had to indicate symptom frequency on a 4-point scale, ranging form 'seldom or never' $(=0)$ to 'usually or all the time' $(=4)$. Higher scores indicated more depressive symptoms (Bouma et al., 1995).

A total of $N=108$ participants were recruited of whom 60 were randomly assigned to the experimental and the waiting list control condition, which was necessary for effect evaluation (Hoogenhout et al., under review). All others did not meet inclusion criteria or refused to participate after they received more information about the intervention program and the experiment (see Figure 1). 


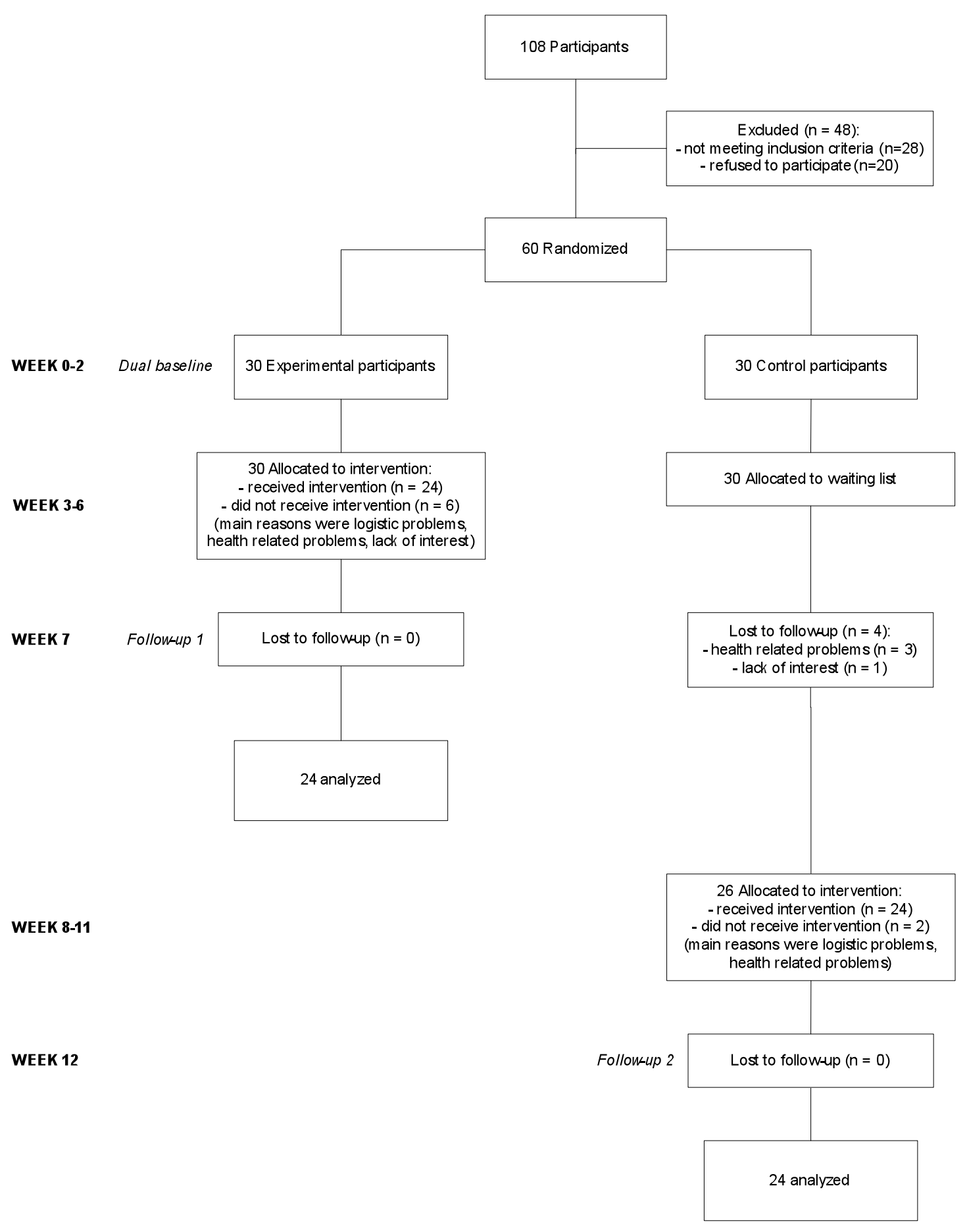

Figure 1 Flowchart of participants

Participants' characteristics are listed in Table 2. Mean age of the total sample (i.e., experimental and waiting list control participants together) was 66.05 years $( \pm 4.32)$.

Mean level of education was 4.07 ( \pm 1.95$)$. 
Table 2 Participants' characteristics: means and standard deviations

\begin{tabular}{llll}
\hline & $\begin{array}{l}\text { Total group } \\
(N=60)\end{array}$ & $\begin{array}{l}\text { Experimental group } \\
(n=30)\end{array}$ & $\begin{array}{l}\text { Control group } \\
(n=30)\end{array}$ \\
\hline Age (years) & $66.05( \pm 4.32)$ & $66.00( \pm 4.23)$ & $66.10( \pm 4.48)$ \\
Educational level (8-point scale) & $4.07( \pm 1.95)$ & $4.14( \pm 2.03)$ & $4.00( \pm 1.90)$ \\
Marital status (\% married) & $57.9 \%$ & $51.7 \%$ & $64.3 \%$ \\
EPQ-Extraversion (range 0-19) & $9.93( \pm 3.36)$ & $9.88( \pm 3.19)$ & $9.96( \pm 3.56)$ \\
EPQ-Neuroticism (range 0-22) & $8.26( \pm 5.16)$ & $8.31( \pm 5.55)$ & $8.21( \pm 4.86)$ \\
CES-D (range 0-60) & $13.03( \pm 10.46)$ & $12.48( \pm 10.06)$ & $13.59( \pm 11.00)$ \\
MMSE & $29.18( \pm .99)$ & $29.24( \pm .99)$ & $29.11( \pm .99)$
\end{tabular}

Note. EPQ = Eysenck Personality Questionnaire; CES-D = Centre of Epidemiologic Studies Depression Scale; MMSE $=$ Mini Mental State Examination

\section{Measures}

\section{Participants' appreciation}

Within one week after the end of the intervention, participants were asked to indicate how they felt about the number, duration, and frequency of the sessions. They were also asked how they felt about the group size. Perceptions of the total quantity of information per session, and the extent to which the information was repeated were rated. Participants were asked to give their opinion about the way information was offered (i.e., PowerPoint presentation, handouts, and session summaries), the opportunity to ask questions, and the possibility to discuss topics. Questions could be answered on a 5-point scale. For example: 'In my opinion, the frequency of the sessions (i.e., twice a week for four consecutive weeks) was... : 1) far too little, 2) too little, 3) good, 4) too much, 5) far too much'. Afterwards, answers were categorized into three categories (e.g., too little, good, too much).

Participants were asked to evaluate the content of the sessions, peer support, and homework assignments. 'Evaluation of sessions' was measured by asking participants to rate whether the sessions were informative, useful, interesting, and enjoyable on a 5-point scale ranging from 1) not at all, to 5) very much. Afterwards a mean score was calculated. Likewise, 'evaluation of peer support' was measured using the mean rating of two statements about the extent to which it was informative and enjoyable. To evaluate 'homework assignments' participants were asked to indicate whether the homework assignments were informative, useful, interesting, and enjoyable, and whether they fitted sufficiently to the session's theme. Additionally, 
participants were asked how much time was spent on the homework assignments. Finally, participants were asked to give a global rating of the intervention program (i.e., $1=$ lowest and $10=$ highest).

\section{Self-evaluations after participation}

Participants' were also asked to compare several aspects of their functioning after intervention to their functioning prior to intervention. Selected domains were: a) making cognitive mistakes, b) being hindered by cognitive mistakes, c) being worried about cognitive abilities, d) being afraid about becoming demented, and e) feeling able to cope with cognitive problems. All statements had to be rated on a 5-point scale.

For example: 'Compared to my situation before the intervention, I am 1) much more worried about becoming demented, 2) more worried about becoming demented, 3) just as worried about becoming demented, 4) less worried about becoming demented, 5) much less worried about becoming demented'. A final option was: 9) I was not worried about becoming demented.

\section{Statistical analyses}

Non-parametric Mann-Whitney U tests (on age, CES-D score, EPQ scores, MMSE and educational level) and a Chi-square test for marital status were used to investigate differences between drop-outs and participants who completed the intervention and final assessment. To explore potential associations between background characteristics (i.e., age, educational level, personality traits, and depressive symptoms), and process evaluations and self-evaluations, Pearson's correlation coefficients were calculated. Afterwards, process and self-evaluation scores were regressed on background variables that showed significant correlations to one or more evaluation scores (i.e., age and educational level, and their interaction term). For this purpose, educational level was dichotomized by a median split procedure (i.e., LE low $=$ those with at most intermediate vocational education $=0 ; \mathrm{LE}$ high $=$ those with more than intermediate vocational education $=1)$. Non-significant predictors $(p>.05)$ were excluded from the full models, but no predictor was removed as long as it was also included in a higher order term (Aiken \& West, 1991). All analyses were carried out with PASW 18.0 for Macintosh. 


\section{Results}

\section{Attrition rate}

Of the $N=60$ participants who were included in the study, $n=48$ (i.e., $n=24$ experimental and $n=24$ waiting list control participants) completed the program and the final assessment. The majority of them (56.3\%) attended all eight sessions, $n=17$ (35.4\%) missed one session, and $n=4(8.3 \%)$ missed two sessions. Participants who dropped out reported higher EPQ extraversion scores $(\mathrm{U}=34.000, p=.028)$ than participants who finished the intervention. Drop out was not related to age, educational level, marital status, MMSE scores, EPQ neuroticism scores, or CES-D scores.

\section{Participants' appreciation}

The majority of the participants were satisfied with the total number of sessions $(85.4 \%)$, the duration of each session $(87.5 \%)$, the frequency of the sessions (i.e., twice a week in four consecutive weeks) (79.2\%), and the total quantity of information per session (85.4\%). A moderate number of participants were satisfied with the extent to which the information was repeated (60.4\%). Almost 40 percent of the participants preferred less repetition of the information. Furthermore, the majority of the participants were satisfied with the way in which the information was offered $(97.9 \%)$, the opportunity to ask questions $(87.5 \%)$, and the opportunity to discuss personal topics $(75.0 \%)$. All participants were satisfied with the group size. Participants' mean evaluation of the sessions content was $4.36( \pm .50)$ on a 5-point scale. Peer support was evaluated as $4.22( \pm .59)$ on a 5-point scale. Mean evaluation of the homework assignments was $4.03( \pm .59)$ on a 5-point scale. Participants spent 30 minutes on average to the homework assignments. The intervention received a mean global rating of $7.81( \pm .82)$ on a 10-point scale.

\section{Self-evaluations after participation}

Of all $n=46$ participants who considered themselves forgetful, $n=32(65.2 \%)$ indicated they made (many) fewer cognitive mistakes after intervention. One person indicated to make more mistakes. Of all $n=39$ participants who felt hindered by their cognitive mistakes, $n=29(74.6 \%)$ reported (much) less hindrance. Two participants (4.2\%) reported more hindrance. Of all $n=41$ participants who were worried about 
their cognitive abilities, $n=38(92.7 \%)$ reported being (much) less worried. One participant indicated being much more worried. Of all $n=38$ participants who were afraid about becoming demented, $n=37$ (97.4.\%) reported being (much) less afraid. Of all $n=48$ participants, $n=41(85.4 \%)$ considered themselves to be (much) more capable of handling their cognitive problems.

\section{Participants' characteristics in relation to evaluations}

Older participants preferred more sessions. Higher educated participants preferred more information per session, less repetition of the information, and less frequent sessions. No significant associations were found between other background characteristics (i.e., age, educational level, marital status, depressive symptoms, and personality traits) and participants' process evaluations and self-evaluations. Relevant regression models are shown in Table 3.

Table 3 Linear regression models of evaluation scores following a step-down hierarchical procedure; the full models included age, educational level, age*educational level

\begin{tabular}{|c|c|c|c|c|c|c|}
\hline & Variable & B & Std. Error B & $\mathrm{T}$ & Sig & Adj. $R^{2}$ \\
\hline \multirow[t]{2}{*}{ Number of sessions } & (constant) & 5.027 & .870 & 5.776 & & \\
\hline & Age & -.030 & .013 & -2.261 & .029 & .080 \\
\hline \multirow[t]{2}{*}{ Quantity of information } & (constant) & 3.000 & .065 & 45.958 & & \\
\hline & Educational level & -.263 & .104 & -2.536 & .015 & .123 \\
\hline \multirow[t]{2}{*}{ Repetition of information } & (constant) & 3.276 & .088 & 37.057 & & \\
\hline & Educational level & .303 & .141 & 2.157 & .036 & .092 \\
\hline \multirow[t]{2}{*}{ Frequency of sessions } & (constant) & 3.310 & .073 & 45.203 & & \\
\hline & Educational level & -.258 & .116 & -2.214 & .032 & .096 \\
\hline
\end{tabular}

\section{Discussion}

The present paper presented a new comprehensive educational group intervention for healthy older adults with perceived cognitive problems. This intervention is in line with a growing enthusiasm for multidimensional cognitive interventions for older adults (McDougall, 2009). Contrary to interventions that have been developed from an information-processing framework of cognitive aging (Ball et al., 2002; Floyd \& 
Scogin, 1997; McDougall, 2009; Rebok et al., 2007; Verhaeghen et al., 1992), such multidimensional cognitive interventions exhibited significant effects on, for example, subjective cognitive functioning (Hohaus, 2007; Lachman et al., 1992; Mohs et al., 1998; Troyer, 2001; Valentijn et al., 2005; Van Hooren, Valentijn, Bosma, Ponds, van Boxtel et al., 2007; West et al., 2008; Winocur, Craik et al., 2007).

The comprehensive group intervention that was described in the current paper had a strong educational focus. It offered information about cognitive aging (Craik \& Bialystok, 2006; Salthouse, 1996; Van Hooren, Valentijn, Bosma, Ponds, Van Boxtel et al., 2007) and the influence of several contextual factors (e.g., psychosocial functioning, health, lifestyle, beliefs, and negative aging stereotypes) (Hess, 2005; Mol et al., 2008). Furthermore, several skills and strategies, which enable individuals to cope with and compensate for perceived cognitive deficits in their everyday lives, were discussed (Bäckman \& Dixon, 1992; Dixon, 1995; Dixon et al., 2001; Levine et al., 2007; Van Hooren, Valentijn, Bosma, Ponds, van Boxtel et al., 2007). The intervention was offered in a group format, which was thought to optimize its effectiveness (Flynn \& Storandt, 1990; Valentijn et al., 2005) and to stimulate discussion about beliefs, negative aging stereotypes, and pessimistic and maladaptive attributions (Commissaris et al., 1993; Commissaris et al., 1998; Hess, 2005; Lachman \& McArthur, 1986; Mol et al., 2008). It incorporated principles of selective optimization through compensation (Baltes \& Baltes, 1990) and applied to a contextual perspective of cognitive aging (Hess, 2005). Fundamental to this intervention was the assumption that aging is often accompanied by perceived cognitive losses that are more related to non-cognitive factors (e.g., affect, metacognition, health) than to actual objective cognitive decline (Kliegel \& Zimprich, 2005; Minett et al., 2008; Mol et al., 2006; Zimprich et al., 2003). In our opinion, the only intervention that significantly shared content and characteristics with our program was described by Hohaus (2007). Unlike Hohaus we were able to carry out a fully randomized controlled trial to evaluate its effectiveness (Hoogenhout et al., under review).

The primary aim of the intervention was to improve subjective cognitive functioning. Recently, a randomized controlled trial was carried out in a homogeneous sample of 60 healthy community-dwelling women (aged 60 to 75 years) with perceived age-related cognitive problems. Results indicated that, compared to participants in the waiting list control condition, participants in the 
experimental condition reported less negative emotional reactions towards cognitive functioning one week after the intervention (Hoogenhout et al., under review). The intervention thus improved an important aspect of subjective cognitive functioning.

The present paper presented the results of a process evaluation that was carried out in order to investigate participants' acceptance and appreciation as well as their self-evaluations after intervention. Results showed that a large majority of participants were satisfied with the total number and frequency of the sessions, the amount of information per session, and the group size. Yet, almost 40 percent preferred less repetition of the information. The majority of participants also appreciated the way in which information was offered, the opportunity to ask questions, and the opportunity to discuss personal topics. Appreciation of the session's content, peer support, and homework assignments were also high. The mean global rating of the intervention was 7.81 on a 10-point scale. The majority of participants indicated that they made fewer cognitive mistakes, felt less hindered by their cognitive mistakes, were less worried, were less afraid about becoming demented, and considered themselves more capable of handling their cognitive problems after intervention. Thus the intervention program was not only effective in enhancing subjective cognitive functioning, it was also highly appreciated and accepted by participants and improved their selfevaluations on several important aspects of functioning. This is highly relevant for large-scale implementation (Grol \& Wensing, 2006; Linnan \& Steckler, 2002; Parisi et al., 2007; Schreurs et al., 2003).

Results also indicated that older participants more often wished for more sessions. Furthermore, higher educated participants required more information per session, less repetition of the information, and less frequent sessions. It can be concluded that such demographical background factors should be taken into account when intervention programs are designed. In future times, it is thus important to finetune the content and set-up of intervention programs for specific target groups. This statement is further supported by findings of recent studies that indicated that compliance and response to memory intervention programs were related to background variables, including age and educational level (Bagwell \& West, 2008; Langbaum, Rebok, Bandeen-Roche, \& Carlson, 2009).

It can be concluded that the intervention program that was described in the current paper may offer a valuable contribution to the field of public health care, especially in the face of our rapidly aging Western society. It effectively reduces 
negative emotional reactions towards cognitive functioning and is highly appreciated by participants. Furthermore, participants evaluate their functioning more positive after taking part in the intervention program. The current study described the background and content of the intervention program in detail in order to enable application and replication by other clinicians and researchers. This may enhance the accumulation of knowledge and the improvement of care. 


\section{References}

Aiken, L. S., \& West, S. G. (1991). Multiple regression: Testing and interpreting interactions. Newbury Park, CA: Sage.

Bäckman, L., \& Dixon, R. A. (1992). Psychological compensation: a theoretical framework. Psychological Bulletin, 112, 259-283.

Bagwell, D. K., \& West, R. L. (2008). Assessing compliance: active versus inactive trainees in a memory intervention. Clinical Interventions in Aging, 3, 371-382.

Ball, K., Berch, D. B., Helmers, K. F., Jobe, J. B., Leveck, M. D., Marsiske, M., Morris, J. N., Rebok, G. W., Smith, D. M., Tennstedt, S. L., Unverzagt, F. W., \& Willis, S. L. (2002). Effects of cognitive training interventions with older adults: a randomized controlled trial. Journal of the American Medical Association, 288, 2271-2281.

Baltes, P. B., \& Baltes, M. M. (1990). Psychological perspectives on successful aging: the model of selective optimization with compensation. In P. B. Baltes (Ed.), Successful aging: Perspectives from the behavioral sciences (pp. 1-34). Cambridge: Cambridge University Press.

Blazer, D. G., Hays, J. C., Fillenbaum, G. G., \& Gold, D. T. (1997). Memory complaint as a predictor of cognitive decline: a comparison of African American and White elders. Journal of Aging and Health, 9, 171-184.

Bouma, J., Ranchor, A. V., Sanderman, R., \& Van Sonderen, E. (1995). Measuring symptoms of depression using the CES-D: a manual [Het meten van symptomen van depressie met de CES-D: een handleiding]. Groningen: Noordelijk Centrum voor Gezondheidsvraagstukken, Rijksuniversiteit Groningen.

Cargin, J. W., Collie, A., Masters, C., \& Maruff, P. (2008). The nature of cognitive complaints in healthy older adults with and without objective memory decline. Journal of Clinical and Experimental Neuropsychology, 30, 245-257.

Comijs, H. C., Deeg, D. J., Dik, M. G., Twisk, J. W., \& Jonker, C. (2002). Memory complaints; the association with psycho-affective and health problems and the role of personality characteristics. A 6-year follow-up study. Journal of Affective Disorders, 72, 157-165.

Comijs, H. C., Dik, M. G., Aartsen, M. J., Deeg, D. J., \& Jonker, C. (2005). The impact of change in cognitive functioning and cognitive decline on disability, well-being, and the use of healthcare services in older persons. Results of Longitudinal Aging Study Amsterdam. Dementia and Geriatric Cognitive Disorders, 19, 316-323.

Commissaris, C. J., Jolles, J., Verhey, F. R., Ponds, R. W., Damoiseaux, V., \& Kok, G. J. (1993). Forgetful or demented? Who worries and why? [Vergeetachtig of dement? Wie maakt zich zorgen en waarom?]. Tijdschrift voor Gerontologie en Geriatrie, 24, 144-149.

Commissaris, C. J., Ponds, R. W., \& Jolles, J. (1998). Subjective forgetfulness in a normal Dutch population: possibilities for health education and other interventions. Patient Education and Counseling, 34, 25-32.

Commissaris, C. J., Verhey, F. R., \& Jolles, J. (1996). A controlled study into the effects of psychoeducation for patients with cognitive disturbances. Journal of Neuropsychiatry and Clinical Neuroscience, 8, 429-435.

Craik, F. I., \& Bialystok, E. (2006). Cognition through the lifespan: mechanisms of change. Trends in Cognitive Science, 10, 131-138. 
Craik, F. I., \& Grady, J. G. (2002). Aging, memory, and frontal lobe functioning. In D. T. Stuss \& R. T. Knight (Eds.), Principles of frontal lobe function (pp. 528540). New York: Oxford University Press.

Craik, F. I., \& Salthouse, T. A. (2000). Handbook of aging and cognition. Mahwah, NJ: Lawrence Erlbaum Associates.

Craik, F. I., Winocur, G., Palmer, H., Binns, M. A., Edwards, M., Bridges, K., Glazer, P., Chavannes, R., \& Stuss, D. T. (2007). Cognitive rehabilitation in the elderly: effects on memory. Journal of the International Neuropsychological Society, 13, 132-142.

De Bie, S. E. (1987). Toward a standardization of questions concerning demographic variables in population studies [Standaardvragen 1987 - Voorstellen voor uniformering van vraagstellingen naar achtergrondkenmkernen en interviews]. Leiden, The Netherlands: Leiden University Press.

Dixon, R. A. (1995). Promoting competence through compensation. In L. A. Bond (Ed.), Promoting successful and productive aging (Vol. 1, pp. 220-238). Thousand Oaks, Calif: Sage Publications.

Dixon, R. A., de Frias, C. M., \& Bäckman, L. (2001). Characteristics of self-reported memory compensation in older adults. Journal of Clinical and Experimental Neuropsychology, 23, 650-661.

Floyd, M., \& Scogin, F. (1997). Effects of memory training on the subjective memory functioning and mental health of older adults: a meta-analysis. Psychology and Aging, 12, 150-161.

Flynn, T. M., \& Storandt, M. (1990). Supplemental group discussions in memory training for older adults. Psychology and Aging, 5, 178-181.

Folstein, M. F., Folstein, S. E., \& McHugh, P. R. (1975). "Mini-mental state". A practical method for grading the cognitive state of patients for the clinician. Journal of Psychiatry Research, 12, 189-198.

Geerlings, M. I., Jonker, C., Bouter, L. M., Ader, H. J., \& Schmand, B. (1999). Association between memory complaints and incident Alzheimer's disease in elderly people with normal baseline cognition. The American Journal of Psychiatry, 156, 531-537.

Glisky, E. L., \& Glisky, M. L. (2005). Memory rehabilition in the elderly. In D. T. Stuss, G. Winocur \& I. H. Robertson (Eds.), Cognitive neurorehabilitation (pp. 347-361). Cambridge: Cambridge University Press.

Grol, R. P., \& Wensing, M. (2006). Implementation: effective improvement of health care [Implementatie: effectieve verbetering van de gezondheidszorg]. Maarssen: Elsevier Gezondheidszorg.

Hess, T. M. (2005). Memory and aging in context. Psychological Bulletin, 131, 383406.

Hohaus, L. (2007). Remembering to age successfully: evaluation of a successful aging approach to memory enhancement. International Psychogeriatrics, 19, 137-150.

Hoogenhout, E. M., De Groot, R. H. M., Van der Elst, W., \& Jolles, J. (under review). Effects of a comprehensive educational group intervention in older women with cognitive complaints: a randomized controlled trial.

Jobe, J. B., Smith, D. M., Ball, K., Tennstedt, S. L., Marsiske, M., Willis, S. L., Rebok, G. W., Morris, J. N., Helmers, K. F., Leveck, M. D., \& Kleinman, K. (2001). ACTIVE: a cognitive intervention trial to promote independence in older adults. Controlled Clinical Trials, 22, 453-479. 
Jonker, C., Geerlings, M. I., \& Schmand, B. (2000). Are memory complaints predictive for dementia? A review of clinical and population-based studies. International Journal of Geriatric Psychiatry, 15, 983-991.

Jonker, C., Launer, L. J., Hooijer, C., \& Lindeboom, J. (1996). Memory complaints and memory impairment in older individuals. Journal of the American Geriatrics Society, 44, 44-49.

Jorm, A. F., Christensen, H., Korten, A. E., Jacomb, P. A., \& Henderson, A. S. (2001). Memory complaints as a precursor of memory impairment in older people: a longitudinal analysis over 7-8 years. Psychological Medicine, 31, 441-449.

Kliegel, M., \& Zimprich, D. (2005). Predictors of cognitive complaints in older adults: a mixture regression approach. European Journal of Ageing, 2, 13-23.

Kliegel, M., Zimprich, D., \& Eschen, A. (2005). What do subjective cognitive complaints in persons with aging-associated cognitive decline reflect? International Psychogeriatrics, 17, 499-512.

Lachman, M. E. (1991). Perceived control over memory aging: developmental and intervention perspectives. Journal of Social Issues, 47, 159-175.

Lachman, M. E. (2000). Promoting a sense of control over memory aging. In R. D. Hill, L. Bäckman \& A. Stigsdotter Neely (Eds.), Cognitive rehabilitation in old age. Oxford: Oxford University Press.

Lachman, M. E., \& McArthur, L. Z. (1986). Adulthood age differences in causal attributions for cognitive, physical, and social performance. Psychology and Aging, 1, 127-132.

Lachman, M. E., Weaver, S. L., Bandura, M., Elliott, E., \& Lewkowicz, C. J. (1992). Improving memory and control beliefs through cognitive restructuring and self-generated strategies. Journals of Gerontology, 47, P293-299.

Langbaum, J. B., Rebok, G. W., Bandeen-Roche, K., \& Carlson, M. C. (2009). Predicting memory training response patterns: results from ACTIVE. Journals of Gerontology B Series: Psychological Sciences and Social Sciences, 64, 1423.

Levine, B., Robertson, I. H., Clare, L., Carter, G., Hong, J., Wilson, B. A., Duncan, J., \& Stuss, D. T. (2000). Rehabilitation of executive functioning: an experimental-clinical validation of goal management training. Journal of the International Neuropsychological Society, 6, 299-312.

Levine, B., Stuss, D. T., Winocur, G., Binns, M. A., Fahy, L., Mandic, M., Bridges, K., \& Robertson, I. H. (2007). Cognitive rehabilitation in the elderly: effects on strategic behavior in relation to goal management. Journal of the International Neuropsychological Society, 13, 143-152.

Linnan, L., \& Steckler, A. (2002). Process evaluation for public health interventions and research: an overview. In A. Steckler \& L. Linnan (Eds.), Process evaluation for public health interventions and research (pp. 1-23). San Francisco: John Wiley \& Sons, Inc.

McDougall, G. J., Jr. (2009). A framework for cognitive interventions targeting everyday memory performance and memory self-efficacy. Family and Community Health, 32, S15-26.

Mendes, T., Gino, S., Ribeiro, F., Guerreiro, M., de Sousa, G., Ritchie, K., \& de Mendonca, A. (2008). Memory complaints in healthy young and elderly adults: Reliability of memory reporting. Aging and Mental Health, 12, 177182. 
Minett, T. S., Da Silva, R. V., Ortiz, K. Z., \& Bertolucci, P. H. (2008). Subjective memory complaints in an elderly sample: a cross-sectional study. International Journal of Geriatric Psychiatry, 23, 49-54.

Mohs, R. C., Ashman, T. A., Jantzen, K., Albert, M., Brandt, J., Gordon, B., Rasmusson, X., Grossman, M., Jacobs, D., \& Stern, Y. (1998). A study of the efficacy of a comprehensive memory enhancement program in healthy elderly persons. Psychiatry Research, 77, 183-195.

Mol, M. E., Carpay, M., Ramakers, I., Rozendaal, N., Verhey, F. R., \& Jolles, J. (2007). The effect of perceived forgetfulness on quality of life in older adults; a qualitative review. International Journal of Geriatric Psychiatry, 22, 393400.

Mol, M. E., Ruiter, R. A., Verhey, F. R., Dijkstra, J., \& Jolles, J. (2008). A study into the psychosocial determinants of perceived forgetfulness: implications for future interventions. Aging and Mental Health, 12, 167-176.

Mol, M. E., van Boxtel, M. P., Willems, D., \& Jolles, J. (2006). Do subjective memory complaints predict cognitive dysfunction over time? A six-year follow-up of the Maastricht Aging Study. International Journal of Geriatric Psychiatry, 21, 432-441.

Mol, M. E., van Boxtel, M. P., Willems, D., Verhey, F. R., \& Jolles, J. (2009). Subjective forgetfulness is associated with lower quality of life in middle-aged and young-old individuals: a 9-year follow-up in older participants from the Maastricht Aging Study. Aging and Mental Health, 13, 699-705.

Parisi, J. M., Greene, J. C., Morrow, D. G., \& Stine-Morrow, E. A. (2007). The Senior Odyssey: Participant experiences of a program of social and intellectual engagement. Activities, Adaptation and Aging, 31, 31-49.

Petersen, R. C., Smith, G. E., Waring, S. C., Ivnik, R. J., Tangalos, E. G., \& Kokmen, E. (1999). Mild cognitive impairment: clinical characterization and outcome. Archives of Neurology, 56, 303-308.

Ponds, R. W., Commissaris, C. J., \& Jolles, J. (1997). Prevalence and covariates of subjective forgetfulness in a normal population in The Netherlands. International Journal of Aging and Human Development, 45, 207-221.

Ponds, R. W., \& Jolles, J. (1996). Memory complaints in elderly people: the role of memory abilities, metamemory, depression, and personality. Educational Gerontology, 22, 341-357.

Rebok, G. W., Carlson, M. C., \& Langbaum, J. B. (2007). Training and maintaining memory abilities in healthy older adults: traditional and novel approaches. Journals of Gerontology B Series: Psychological Sciences and Social Sciences, 62 Spec No 1, 53-61.

Salthouse, T. A. (1996). The processing-speed theory of adult age differences in cognition. Psychological Review, 103, 403-428.

Salthouse, T. A. (2006). Mental exercise and Mental aging: evaluating the validity of the "Use it or Lose it" Hypothesis. Perspectives on Psychological Sciences, 1, 68-87.

Sanderman, R., Arrindell, W. A., Ranchor, A. V., Eysenck, H. J., \& Eysenck, S. B. G. (1995). Measuring personality traits with the Eysenck Personality Questionnaire (EPQ) [Het meten van persoonlijkheidskenmerken met de Eysenck Personality Questionnaire (EPQ]. Groningen, The Netherlands: Noordelijk Centrum voor Gezondheidsvraagstukken, Rijksuniversiteit Groningen. 
Schreurs, K. M., Colland, V. T., Kuijer, R. G., De Ridder, D. T., \& Van Elderen, T. (2003). Development, content, and process evaluation of a short selfmanagement intervention in patients with chronic diseases requiring self-care behaviours. Patient Education and Counseling, 51, 133-141.

Stuss, D. T., Robertson, I. H., Craik, F. I., Levine, B., Alexander, M. P., Black, S., Dawson, D., Binns, M. A., Palmer, H., Downey-Lamb, M., \& Winocur, G. (2007). Cognitive rehabilitation in the elderly: a randomized trial to evaluate a new protocol. Journal of the International Neuropsychological Society, 13, 120-131.

Troyer, A. K. (2001). Improving memory knowledge, satisfaction, and Functioning, via an education and intervention program for older adults. Aging, Neuropsychology, and Cognition, 8, 256-268.

Valentijn, S. A., Van Hooren, S. A., Bosma, H., Touw, D. M., Jolles, J., van Boxtel, M. P., \& Ponds, R. W. (2005). The effect of two types of memory training on subjective and objective memory performance in healthy individuals aged 55 years and older: a randomized controlled trial. Patient Education and Counseling, 57, 106-114.

Van Hooren, S. A., Valentijn, S. A., Bosma, H., Ponds, R. W., Van Boxtel, M. P., \& Jolles, J. (2007). Cognitive functioning in healthy older adults aged 64-81: a cohort study into the effects of age, sex, and education. Aging, Neuropsychology, and Cognition, 14, 40-54.

Van Hooren, S. A., Valentijn, S. A., Bosma, H., Ponds, R. W., van Boxtel, M. P., Levine, B., Robertson, I., \& Jolles, J. (2007). Effect of a structured course involving goal management training in older adults: A randomised controlled trial. Patient Education and Counseling, 65, 205-213.

Verhaeghen, P., Marcoen, A., \& Goossens, L. (1992). Improving memory performance in the aged through mnemonic training: a meta-analytic study. Psychology and Aging, 7, 242-251.

Verhey, F. R., Ramakers, I., Jolles, J., Scheltens, P., Vernooij-Dassen, M. J., \& Olde Rikkert, M. (2007). Memory clinics in the Netherlands: development since 1998 [Geheugenpoli's in Nederland: ontwikkelingen sinds 1998]. Tijdschrift voor Gerontologie en Geriatrie, 38, 237-245.

West, R. L., Bagwell, D. K., \& Dark-Freudeman, A. (2008). Self-Efficacy and Memory Aging: The Impact of a Memory Intervention Based on SelfEfficacy. Aging, Neuropsychology, and Cognition, 15, 302-329.

Willis, S. L., Tennstedt, S. L., Marsiske, M., Ball, K., Elias, J., Koepke, K. M., Morris, J. N., Rebok, G. W., Unverzagt, F. W., Stoddard, A. M., \& Wright, E. (2006). Long-term effects of cognitive training on everyday functional outcomes in older adults. Journal of the American Medical Association, 296, 2805-2814.

Winblad, B., Palmer, K., Kivipelto, M., Jelic, V., Fratiglioni, L., Wahlund, L. O., Nordberg, A., Bäckman, L., Albert, M., Almkvist, O., Arai, H., Basun, H., Blennow, K., de Leon, M., DeCarli, C., Erkinjuntti, T., Giacobini, E., Graff, C., Hardy, J., Jack, C., Jorm, A., Ritchie, K., van Duijn, C., Visser, P., \& Petersen, R. C. (2004). Mild cognitive impairment--beyond controversies, towards a consensus: report of the International Working Group on Mild Cognitive Impairment. Journal of Internal Medicine, 256, 240-246.

Winocur, G., Craik, F. I., Levine, B., Robertson, I. H., Binns, M. A., Alexander, M., Black, S., Dawson, D., Palmer, H., McHugh, T., \& Stuss, D. T. (2007). 
Cognitive rehabilitation in the elderly: overview and future directions. Journal of the International Neuropsychological Society, 13, 166-171.

Winocur, G., Palmer, H., Dawson, D., Binns, M. A., Bridges, K., \& Stuss, D. T. (2007). Cognitive rehabilitation in the elderly: an evaluation of psychosocial factors. Journal of the International Neuropsychological Society, 13, 153-165.

Zacks, R. T., Hasher, L., \& Li, K. Z. H. (2000). Human memory. In F. I. M. Craik \& T. A. Salthouse (Eds.), The handbook of aging and cognition (Vol. 2, pp. 293357). Mahwah, NJ: Erbaum.

Zimprich, D., Martin, M., \& Kliegel, M. (2003). Subjective cognitive complaints, memory performance, and depressive affect in old age: a change-oriented approach. International Journal of Aging and Human Development, 57, 339366. 